University of Nebraska - Lincoln

DigitalCommons@University of Nebraska - Lincoln

Public Health Resources

Public Health Resources

8-1-2014

Interferons: Success in anti-viral immunotherapy

Fan ching Lin

National Cancer Institute at Frederick, fanching.lin@nih.gov

Howard A. Young

National Cancer Institute at Frederick, younghow@mail.nih.gov

Follow this and additional works at: https://digitalcommons.unl.edu/publichealthresources

Part of the Medical Sciences Commons, and the Public Health Commons

Lin, Fan ching and Young, Howard A., "Interferons: Success in anti-viral immunotherapy" (2014). Public Health Resources. 606.

https://digitalcommons.unl.edu/publichealthresources/606

This Article is brought to you for free and open access by the Public Health Resources at DigitalCommons@University of Nebraska - Lincoln. It has been accepted for inclusion in Public Health Resources by an authorized administrator of DigitalCommons@University of Nebraska - Lincoln. 
Mini review

\title{
Interferons: Success in anti-viral immunotherapy
}

\author{
Fan-ching Lin *, Howard A. Young \\ Laboratory of Experimental Immunology, Cancer and Inflammation Program, Center for Cancer, Research, National Cancer Institute, Frederick, MD 21702, USA
}

\section{A R T I C L E I N F O}

Article history:

Available online 29 July 2014

\section{Keywords:}

Antiviral therapy

IFN- $\alpha / \beta$

IFN- $\gamma$

IFN- $\lambda$

\begin{abstract}
A B S T R A C T
The interferons (IFNs) are glycoproteins with strong antiviral activities that represent one of the first lines of host defense against invading pathogens. These proteins are classified into three groups, Type I, II and III IFNs, based on the structure of their receptors on the cell surface. Due to their ability to modulate immune responses, they have become attractive therapeutic options to control chronic virus infections. In combination with other drugs, Type I IFNs are considered as "standard of care" in suppressing Hepatitis C (HCV) and Hepatitis B (HBV) infections, while Type III IFN has generated encouraging results as a treatment for HCV infection in phase III clinical trials. However, though effective, using IFNs as a treatment is not without the need for caution. IFNs are such powerful cytokines that affect a wide array of cell types; as a result, patients usually experience unpleasant symptoms, with a percentage of patients suffering system wide effects. Thus, constant monitoring is required for patients treated with IFN in order to reach the treatment goals of suppressing virus infection and maintaining quality of life.
\end{abstract}

(c) 2014 Elsevier Ltd. All rights reserved.

\section{Introduction}

The interferons (IFNs) were first described in 1957 as a heterogeneous class of soluble glycoproteins with strong antiviral activities. The induction of their expression occurs in response to viruses or bacteria infection. IFNs are classified into three types of IFNs, Type I, II and III, based on the structure of their receptors on the cell membrane surface. Due to their ability to modulate immune responses, they have been considered as a treatment option for several cancers and autoimmune diseases (Table 1). With the development of recombinant IFNs, IFNs becomes even more attractive therapeutic options since their supply was no longer limited. As a consequence of the clinical failures in controlling chronic virus infection using only antiviral drugs, due to the generation of drug resistant strains, treatment options like IFNs that target the host immune response rather than specific viral proteins, become an important component of the treatment regimen. Indeed, in recent years, Type I IFNs have been part of the standard treatment for HCV and HBV infections and the appearance of IFN-resistant viral subpopulations has not been observed. In addition, there is a growing interest in testing the antiviral efficacy of the new member of IFN, Type III IFN, in HCV infection based on the fact that the Type III IFN receptor is more restricted in

\footnotetext{
* Corresponding author.

E-mail addresses: fanching.lin@nih.gov (F.-c. Lin), younghow@mail.nih.gov (H.A. Young).
}

its expression and is present on hepatocytes. In this review, we will discuss the biology and the antiviral activities of the IFNs, as well as their use in antiviral therapy in human diseases.

\section{Type I interferons: interferon-alpha/beta (IFN- $\alpha / \beta)$}

\subsection{Type I interferons signaling pathway}

Type I IFNs belong to the class II family of $\alpha$-helical cytokines, including, IFN- $\gamma$, IFN- $\lambda$ s (Type III IFNs), IL-10 and several IL-10 homologs (IL-19, IL-20, IL-22, IL-24 and IL-26). Type I IFNs can be produced by all nucleated cells in response to viral or microbial infections. In humans, the Type I IFN family is composed of 12 IFN$\alpha$ subtypes encoded by 14 genes, IFN- $\beta$ encoded by a single IFNB gene, and IFN- $\varepsilon$, IFN- $\kappa$ and IFN- $\omega$ [1]. In this review, we will focus on the two well-characterized Type I IFNs, IFN- $\alpha$ and IFN- $\beta$. All Type I IFNs signal by binding to the same heterodimeric receptor IFN $\alpha / \beta$ receptor (IFNAR). IFNAR is expressed by nearly all cell types and consists of IFNAR1 and IFNAR2 subunits that are associated with tyrosine kinase 2 (TYK2) and Janus kinase 1(JAK1) respectively. Binding to IFNAR results in activation of TYK2 and JAK1 that phosphorylate the tyrosine residues in the IFNAR cytoplasmic domains, thus creating docking sites for signal transducers and activators of transcription (STATs), (STAT1, STAT2 and STAT3 in most cell types), which are then targeted by JAK for phosphorylation. Phosphorylated STATs (PSTATs) form either homodimers or heterodimers and translocate into the nucleus. The pSTAT1 homodimer binds to gamma-activated sequence (GAS, 
Table 1

Current FDA approved IFN therapeutic agents.

\begin{tabular}{|c|c|c|c|}
\hline Brand name & Generic name & Manufacturers & Descriptions \\
\hline \multicolumn{4}{|l|}{ Type I IFNs } \\
\hline Alferon $\mathrm{N}$ & IFN- $\alpha \mathrm{n} 3$ & Hemispherx & Approved for the treatment of genital and perianal warts caused by human papillomavirus (HPV) \\
\hline Infergen & IFN- $\alpha \operatorname{con} 1$ & Intermune Pharms & Approved for the treatment of $\mathrm{HCV}$ \\
\hline Pegasys & Peg-IFN- $\alpha 2 \mathrm{a}$ & Roche & $\begin{array}{l}\text { Approved for the treatment of HBV adult patients negative, HCV patients } 5 \text { years of age and older } \\
\text { not previously treated with IFN- } \alpha \text {, and HCV/HIV coinfected patients. }\end{array}$ \\
\hline Referon A & IFN- $\alpha 2 a$ & Roche & $\begin{array}{l}\text { Approved to treat hairy cell leukemia, AIDS-related Kaposi's sarcoma, and chronic myelogenous } \\
\text { leukemia. }\end{array}$ \\
\hline Intron A & IFN- $\alpha 2 b$ & Schering & $\begin{array}{l}\text { Approved for the treatment of HBV patients } 1 \text { year of age or older and HCV patient } 18 \text { years of age or } \\
\text { older }\end{array}$ \\
\hline PegIntron/Sylaton & Peg-IFN- $\alpha 2 b$ & Schering & $\begin{array}{l}\text { Approved for the treatment of HCV patients } 18 \text { years of age or older who previously untreated with } \\
\text { IFN- } \alpha\end{array}$ \\
\hline Rebif & IFN- $\beta 1 \mathrm{a}$ & Merk Serono & Approved for the treatment of multiple sclerosis \\
\hline Avonex & IFN- $\beta 1 \mathrm{a}$ & Biogen Idec & Approved for the treatment of multiple sclerosis \\
\hline Betaseron & IFN- $\beta 1 \mathrm{~b}$ & Bayer & Approved for the treatment of multiple sclerosis \\
\hline Extavia & IFN- $\beta 1 b$ & Novartis & Approved for the treatment of multiple sclerosis \\
\hline \multicolumn{4}{|l|}{ Type II IFN } \\
\hline Actimmune & IFN- $\gamma 1 \mathrm{~b}$ & Vidara Therapeutics & Approved for the treatment of chronic granulomatous disease, and severe, malignant osteopetrosis \\
\hline
\end{tabular}

TTCNNNGAA) in the promoter region of interferon stimulated genes (ISGs) and initiates the transcription of these target genes, while the homodimer formed by pSTAT3 activates the transcription of genes containing the enhancer sequence STAT3-binding element.

Phosphorylated STAT1 and STAT2 form a heterodimer that leads to the recruitment of IRF9 and the formation of the IFNstimulated gene factor 3 (ISGF3) complex. This complex then transfers to the nucleus and binds to IFN-stimulated response elements (ISREs) in the promoter region of IFN responsive genes (ISGs) to initiate transcription of genes that are pivotal for Type I antiviral activities (Fig. 1) [2,3]. In addition to STAT1, STAT2 and STAT3, it has been shown that Type I IFN can also activate STAT4, STAT5 and STAT6 in certain cell types [4]. Activation of JAK can also induce several alternative signaling pathways, including the PI3K, NF-kB and MAPK pathways, which further amplifies Type I IFN signaling strength and magnitude.

\subsection{Antiviral activity}

Type I IFN induces an array of proteins that interfere with virus replication in order to restrict and limit viral spread from cell to cell [5,6]. 2'-5'-oligoadenylate synthetase (OAS) is an enzyme induced by Type I IFN that activates latent nuclease RNaseL which then mediates viral RNA degradation. Another induced enzyme, protein kinase RNA-activated (PKR), a member of the eukaryotic initiation factor $2 \alpha$ family, prevents the recycling of guanidine diphosphate which in turns blocks viral RNA translation. Other notable antiviral proteins induced by Type I IFN are myxovirus resistance (Mx) GTPases which restrict viral nucleocapsid localization, interferon stimulated gene 15 (ISG15) and tripartite motif (TRIM) protein which interfere with the release of viral particles, as well as APOBEC3, a protein that induces hypermutation of viral DNA. To confine and localize the infection, Type I IFNs also can activate the apoptosis mechanism to eliminate virus infected cells

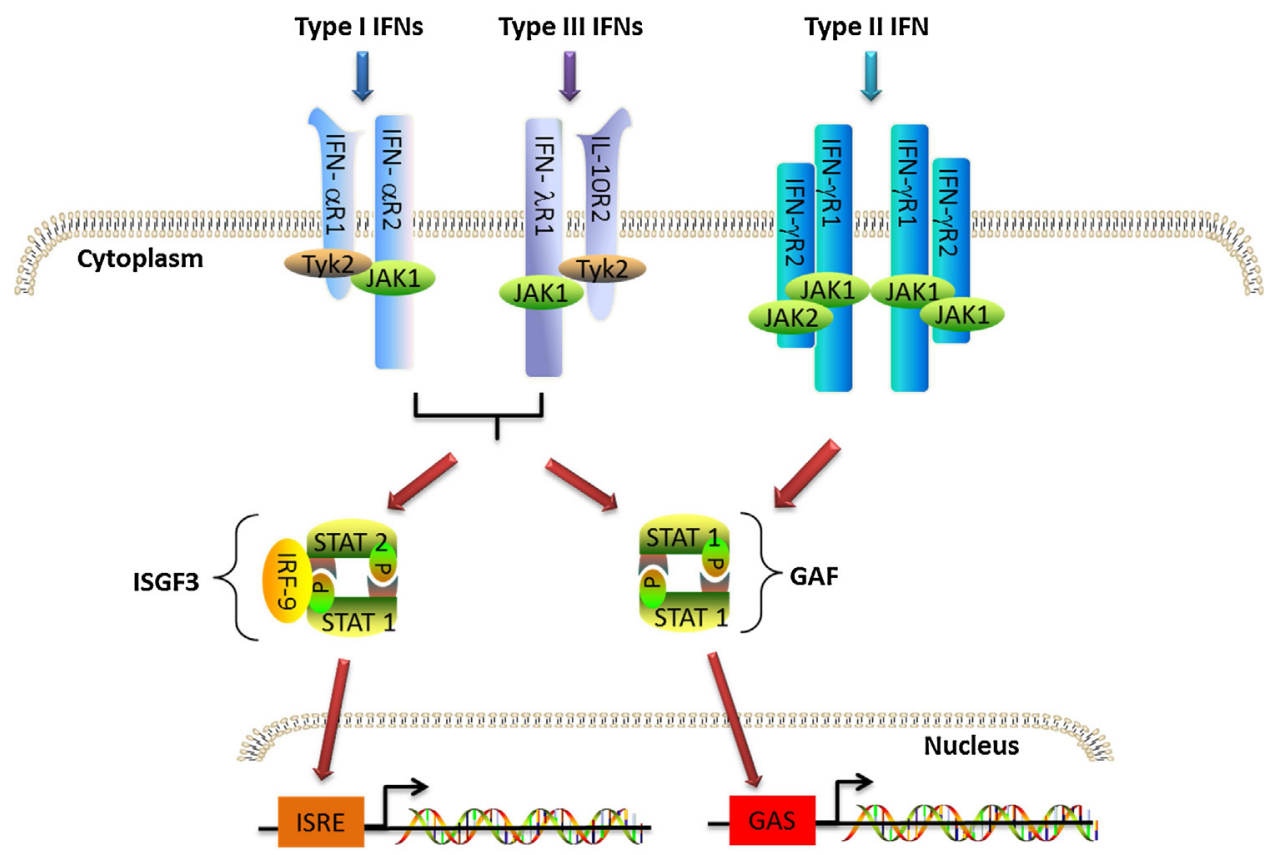

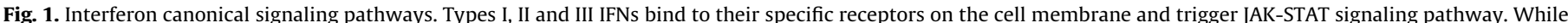

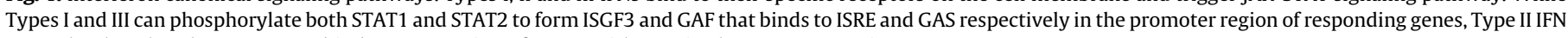
can only phosphorylate STAT1 and induce expression of genes with GAS in the promoter region. 
by up regulating Fas ligand (FasL), PDL-1 and TRAIL. In addition to activating the antiviral mechanism in the infected cells, Type I IFN can also limit virus infection by modulating both innate and adaptive immunity. Type I IFNs directly activate NK cells to enhance their cytotoxicity to eliminate infected cells and confine the infection. However, complete elimination of intracellular infection by pathogens requires activation of the adaptive immune response and the Type I IFNs have an active role in this activation process. Type I IFNs promote the maturation of dendritic cells (DCs) that facilitate CD4+ T cell differentiation into either Th1 or Th2 cells $[5,6]$. Studies have shown that Type I IFN experienced APCs are capable of cross-presentation and stimulate naïve CD8+ T cells, resulting in clonal expansion and proliferation. These Type I IFN experienced DCs have increased expression of chemokines that recruit NK, T and B cells to the site of infection, and IL-15 which is important in NK and CD8+ memory cell maintenance. All these cell intrinsic and extrinsic effects of Type I IFNs prepare the host immune system to mount an effective response against intracellular pathogens.

\subsection{IFN- $\alpha$ as a therapeutic agent for HCV infections}

Chronic infection with HCV is a major health problem with approximately 180 million people infected worldwide. While more than $80 \%$ of HCV chronic infection is asymptomatic, $5-30 \%$ of infected patients develop cirrhosis and sometimes advance to severe liver disease including variceal hemorrhage and hepatocelluar carcinoma (HCC). Currently, there are several drugs targeting virus replication that have been FDA approved for clinical use. However, due to the high incidence of drug resistant $\mathrm{HCV}$ strains, the consequences of a promiscuous RNA polymerase, the treatment with the antiviral drugs alone has been less than effective although new antiviral drugs show more promise [7]. With its extensive antiviral activity, recombinant IFN- $\alpha$ was first used in HCV treatment in 1986. However, because of the rapid absorption, short half-life and rapid elimination by the kidney, the result was less than desirable, even with the addition of the nucleoside analogue ribavirin. To allow for slower absorption and maintenance of sustained and stable blood levels, pegylated IFN, synthesized by attaching a polyethylene glycol (PEG) moiety, was introduced into the clinic in 2001 [8,9]. The change was less traumatic for the patients as it only required a weekly injection of Type I IFN, instead of injection three times a week. Currently, the accepted standard treatment for chronic HCV infection is weekly subcutaneous pegylated IFN- $\alpha$ (PEG-IFN- $\alpha$ ) injection with oral daily ribavirin. The treatment goal is to achieve sustained virologic response (SVR) with undetectable HCV RNA by the end of the treatment period. PEG-IFN- $\alpha /$ ribavirin treatment in $\mathrm{HCV}$ infection produces highly desirable results. Approximately $80 \%$ of patients achieve SVR at the end of treatment period. Currently, there are two PEG-IFN- $\alpha$ s available in clinical use, IFN- $\alpha 2 \mathrm{a}$ and IFN- $\alpha 2 \mathrm{~b}$, for $\mathrm{HCV}$ treatment. While the IFN- $\alpha 2$ subtype has a lower binding affinity to its receptor that is associated with a lower antiproliferative potency, there is no difference in the antiviral effect compared to other subtypes [10]. However, comparing IFN- $\alpha 2 \mathrm{a}$ and IFN- $\alpha 2 b$ for efficacy in HCV therapy has generated conflicting results that could be explained by the different dosing regimens, (i.e. fixed for PEG-IFN- $\alpha 2 a$ and weight-based for PEG-IFN- $\alpha 2 b$ ), and slightly different dosing of ribavirin. Furthermore, the HCV subjects treatment history could affect the interpretation of results in these trials since many HCV patients are co-infected with other pathogens, including HIV, and these co-infections may well affect the treatment outcome [11].

Though successful, IFN treatment often is accompanied with undesirable systemic side effects, since virtually all cell types express IFNAR. Common IFN- $\alpha$ induced side effects including fatigue, headache, pyrexia, myalgia, rigors and psychiatric symptoms. Anemia, one of the common hematological abnormalities observed during treatment, is mainly caused by ribavirin, while neutropenia and thrombocytopenia are a result of IFN- $\alpha$ treatment [12]. Dose reduction or treatment discontinuation may be necessary depending upon the severity of the symptoms. Due to the potential systemic side effects, other IFNs molecules, including, albumin-IFN- $\alpha$, IFN- $\lambda$ (discussed in detail later in this review) and consensus IFN- $\alpha$, have been under study as potential candidates to replace PEG-IFN- $\alpha$. Albumin IFN- $\alpha 2 b$ is a product of a fusion gene with the genes for IFN- $\alpha$ and human serum albumin. It is a 85.7 kDa molecule that retains the antiviral properties of IFN- $\alpha$ with a 6-day half-life that is $2-4$ fold longer than PEG-IFN- $\alpha$ [13]. The long half-life of albumin IFN- $\alpha$ allows a 2 -week or even a 4 -week dosing regimen which might limit the incidence of IFN- $\alpha$ related side effects. Though a phase I/II trial showed promising results, the results of a phase III trial raised concerns regarding the safety of albumin IFN- $\alpha$ due to an increased incidence of not only common IFN- $\alpha$ associated side effects but also pulmonary complications as compared to the PEG-IFN- $\alpha 2$ a treatment groups. As a consequence, the application for FDA approval has since been dropped $[14,15]$.

Consensus IFN (CIFN) is a recombinant protein from a consensus gene that consists of the most commonly observed amino acids from several Type I IFN subtypes. CIFN has been shown to have $10-100$ times higher antiviral activity compared to standard IFN- $\alpha$, thus permitting a lower dosing regimen and potentially limiting the incidence of IFN- $\alpha$ type side effects. However, along with the stronger antiviral activities, CIFN still has the disadvantages of recombinant IFN- $\alpha$, i.e. rapid absorption, short half-life and rapid elimination by the kidney. Thus, patients require daily injection to maintain a SVR. An early phase III trial, designed to evaluate the efficacy of CIFN, showed that CIFN monotherapy produced a higher rate of SVR compared to the treatment with IFN- $\alpha 2 \mathrm{~b}$. Furthermore, a treatment regimen combining CIFN with ribavirin was shown to be effective in treating PEG-IFN- $\alpha /$ ribavirin non-responders in a clinical trial [16]. Based on these promising phase III clinical trial results, CIFN treatment is currently approved in the USA [11,17].

The combination of PEG-IFN/ribavirin has been the standard of care for HCV infection for the past decade. However, the success of treatment has been limited by suboptimal SVR rates in treatment resistant patients, poor tolerability, and cumbersome treatment regime. A huge effort has been made to optimize the HCV treatment regimen in the hope to overcome the limitation of PEGIFN/ribavirin treatment. Extensive knowledge gained so far regarding the $\mathrm{HCV}$ life cycle has stimulated the development of direct antiviral agents (DAA) which target viral proteins to interfere with their replication. There are four major groups of DAAs, NS3/4A protease inhibitor (PIs), NS5B nucleoside polymerase inhibitors (NPIs), NS5B non-nucleoside polymerase inhibitors (NNPIs) and NS5A inhibitors. In 2011, two PIs, telaprevir and boceprevir were approved by FDA and when used in combination with PEG-IFN/ribavirin treatment, significantly increased the SVR rate in treated patients. There are currently several promising DAAs in clinical trials to investigate their efficacy as monotherapy or in conjunction with ribavirin or PEG-IFN/ribavirin. Though some showed hepatotoxicity, most DAAs tested were well tolerated and showed potent antiviral activity even in treatment resistant patients. Most showed desirable SVR as a monotherapy and achieved higher SVR when combined with PEG-IFN and ribavirin $[18,19]$. The success in DAAs in clinical trials also stimulated the development of IFN free treatment regimen by combining DAAs with different functional profiles. IFN free treatment regimen is beneficial for patients with poor tolerance to IFN and/or who have suffered from psychological disorders. Currently, there are clinical 
trials investigating the efficacy of different DAA combinations as anti-HCV therapy. The clinical results so far indicate that DAA combination treatment potentially could have a shorter treatment duration with better SVR [18]. Because of the undesirable side effects and poor SVR of PEG-IFN/ribavirin regimen, the future of HCV therapy will focus on developing IFN free treatment as the standard of care. With the success in the clinical trials, one can foresee the availability of such treatment in the near future. However, the challenge in DAA combination treatment approaches is the concern about selecting drug resistant strains of the virus. Patients who are infected with such strains will have only one feasible treatment PEG-IFN/ribavirin as interferon resistance has not been observed. Thus, the traditional regimen with IFN- $\alpha$ will remain a critical part in anti-HCV therapy.

\subsection{IFN- $\alpha$ as a therapeutic agent for $H B V$ infections}

In addition to its use for the treatment of HCV, PEG-IFN- $\alpha 2 \mathrm{a}$ also has been used for treating chronic HBV infection. Even with an effective vaccine, there are approximately 350-400 million people infected with $\mathrm{HBV}$, an infection rate that poses a serious global health problem. Thought non-cytopathic, HBV is capable of triggering immune responses and results in persistent hepatic inflammation that ultimately leads to cirrhosis and HCC [20]. PEG-IFN- $\alpha 2$ a was shown to effectively clear serum hepatitis B e antigen (HBeAg), decrease the HCC rate and improve survival in chronic HBV infected patients. Several studies also showed that the PEG-IFN- $\alpha 2 \mathrm{a}$ has a long lasting effect in maintaining negative serum $\mathrm{HBeAg}$ after treatment when compared to nucleoside analogues (NA), such as lamivudine (LMV), adefovir (ADV), entecavir (ETV) and telbivudine (LdT) [21]. Though successful, using PEG-IFN- $\alpha 2$ a as a monotherapy was shown to be less than ideal. In addition to the unpleasant side effects induced by IFN- $\alpha$ as mentioned in this review, the percentage of patients who achieved HBeAg seroconversion (from HBsAg to hepatitis B surface antibody (anti-HBsAg)) is usually less than $35 \%$ with a relapse incidence of $5-10 \%$ [22]. Nevertheless, since the IFN side effects can be managed by dose reduction or termination of treatment, PEG-IFN- $\alpha 2 a$ still remains the standard of care for chronic HBV infection according to World Health Organization recommendations [23]. In order to improve the treatment results, several groups have explored the option of combing PEG-IFN- $\alpha 2$ a with NA. In HBsAg positive chronic HBV patients, the rates of undetectable serum HBV DNA and seroconversion were higher in the group treated with combination therapy. In addition, the combination therapy also showed superiority in maintaining long term $\mathrm{HBeAg}$ clearance and seroconversion after the end of treatment period when compared to PEG-IFN- $\alpha 2 a$ monotherapy [24-26]. During PEGIFN- $\alpha 2$ a treatment, some patients lose serum HBeAg while maintaining high levels of HBV DNA. These HBeAg negative patients have been shown to have poor virological and serological responses to PEG-IFN- $\alpha 2 a$ treatment and a higher rate of virological relapse. Extended PEG-IFN- $\alpha 2 a$ treatment beyond the traditional 48-week treatment regimen was shown to improve the efficacy among $\mathrm{HBeAg}$ negative patients. In addition, sequential therapy with NA and PEG-IFN- $\alpha 2 a$, monotherapy with NA or PEG-IFN- $\alpha 2 a$ followed by combination therapy or mono therapy with NA or PEG-IFN- $\alpha 2 a$, has been shown to be a promising treatment for in $\mathrm{HBsAg}$ negative patients as more than $50 \%$ pf HBsAg negative patients were able to respond to treatment, and achieved SVR with significant decreased in serum HBV DNA $[27,28]$. Since these studies were done with a small cohort, a clinical trial with significant numbers of recruits will be required to further validate the efficacy of sequential therapy in HBsAg negative patients.

\subsection{IFN- $\beta$ as a therapeutic agent for HCV infection}

While IFN- $\beta$ is most notably used as treatment in multiple sclerosis, it also has been used in antiviral therapy since IFN- $\beta$ has been shown to have comparable antiviral activity to IFN- $\alpha$. The efficacy of IFN- $\beta$ as an alternative therapeutic option or in combination with standard care for HCV infection has been extensively investigated in Asia, including Japan, Korea and China [29-31]. These studies not only proved the efficacy of IFN- $\beta$ as an $\mathrm{HCV}$ therapy, but also showed promising results in overcoming the treatment block in patients who had poor responses to IFN- $\alpha-2 b /$ ribavirin. Ishikawa et al. showed a higher percentage of patients infected with HCV genotype 1, who were poor responders to IFN$\alpha-2 b /$ ribavirin treatment, achieved SVR when treated with IFN- $\beta$ in the first 2 weeks followed by IFN- $\alpha-2 b /$ ribavirin compared to IFN- $\alpha-2 b$ /ribavirin alone. Furthermore, a recent study showed a 2week lead-in IFN- $\beta /$ ribavirin treatment followed by 46 weeks of PEG-IFN- $\alpha /$ ribavirin treatment significantly reduced the viral load in patients carrying the IL-28 risk allele, a group that does not respond to PEG-IFN- $\alpha /$ ribavirin treatment [32]. In addition, treatment with IFN- $\beta$ exhibited a low incidence of adverse effects as compared to IFN- $\alpha$. However, IFN- $\beta$ treatment is rather cumbersome as only a recombinant form of IFN- $\beta$ is available for treatment. This form of IFN- $\beta$ has a shorter half-life and requires a once daily or twice daily administration to reach a desirable outcome.

\subsection{Type I IFN as an adjuvant for antiviral therapy}

In addition to a strong antiviral agent, Type I IFN also is a powerful immunomodulation. Thus, multiple studies have utilized Type I IFN as an adjuvant to enhance the efficacy of a vaccine regimen. A study investigating the efficacy of IFN- $\alpha$ as an adjuvant for the HBV vaccine in induction of an anti-HBeAg antibody response in vaccine non-responders found a marginal increase in the percentage of patients who developed antibody; $53 \%$ of IFN- $\alpha$ treated subjects compared to $41 \%$ in the placebo group [33]. However, in a more recent study incorporating IFN- $\alpha$ in an HBV vaccine regimen in healthy subjects, no difference in seroconversion rates and $\mathrm{T}$ cell responses between IFN- $\alpha$ and placebo groups were observed [34].

Since a trend in an enhanced activation level in APCs was observed, the authors speculate that an evaluation in the forms of IFN- $\alpha$, dosage and vaccine regimen that should be used in such studies is needed in order to accurately assess the efficacy of IFN- $\alpha$ as an adjuvant.

\section{Type II interferon: interferon-gamma (IFN- $\gamma$ )}

\subsection{IFN-ysignaling pathway}

The active IFN- $\gamma$ molecule consists of two antiparallel and intercalating polypeptides that fold into a twofold symmetry. The dimer formation and folding are important to its biological function and have been shown to be conserved among vertebrates [35]. While virtually all cells express IFN- $\gamma$ receptors, the source of IFN- $\gamma$ is restricted to certain cell types, namely natural killer (NK) cells, T cells and NKT cells. The biological activity of IFN- $\gamma$ is initiated upon binding to its receptor which consists of two ligandbinding IFN- $\gamma$ R1 chains whose expression level among cells is consistently high and two signal-transducing IFN- $\gamma \mathrm{R} 2$ chains whose expression level is determined by the cell types and activation status of the cells. IFN- $\gamma$ first binds to IFN- $\gamma$ R1, and the formation of IFN- $\gamma$ : IFN- $\gamma$ R1 complex facilitates its association with IFN- $\gamma$ R2, that then initiates the downstream signaling events [36]. The formation of this ligand receptor complex allows JAK1 
and JAK2, which constitutively bind IFN- $\gamma \mathrm{R} 1$ and IFN- $\gamma \mathrm{R} 2$ respectively through their $\mathrm{N}$-terminal domains, to transactivate each other. The activated JAKs then phosphorylate the tyrosine residue on each IFN- $\gamma$ R1 chain to form the docking site for STAT1 which is then phosphorylated by the JAKs. The pSTAT1s form a homodimer that translocates into the nucleus and initiates the transcription of the target genes (Fig. 1) [37].

The JAK/STAT pathway is the primary signaling pathway initiated by IFN- $\gamma$ stimulation. Similar to Type I IFNs, IFN- $\gamma$ also can activate STAT1-independent pathways such as MAP kinase, $\mathrm{PI} 3 \mathrm{~K}$ and the NF- $\mathrm{B}$ B signaling pathway as all have been shown to be activated after IFN- $\gamma$ treatment [38]. In addition, it has been shown that IFN- $\gamma$ can also induce a non-canonical signaling pathway. In this pathway, IFN- $\gamma$, together with one of its receptor subunit IFNGR1 and pSTAT1, translocate to the nucleus and induce gene expression by binding to GAS elements in the promoter region of IFN inducible genes [39].

\subsection{IFN- $\gamma$ antiviral activities}

During virus infection, IFN- $\gamma$ can turn on the cellular antiviral mechanism by inducing the expression of several antiviral proteins. In addition to PKR, OAS and Mx GTPase mentioned in the previous section, IFN- $\gamma$ can also trigger the expression dsRNAspecific adenosine deaminase (ADAR) which inhibits virus replication by editing or causing mis-translation of viral proteins. Similar to Type I IFNs, IFN- $\gamma$ can induce apoptosis by up regulating FasL to eliminate virus infected cells. Furthermore, IFN- $\gamma$ enhances the expression of Type I IFN expression which further augments the antiviral state of the cells. In addition to induction of antiviral proteins, IFN- $\gamma$ also exercises its antiviral activity by modulating both innate and adaptive immune responses. First, IFN- $\gamma$ can induce the expression of proinflammatory cytokines and chemokines by endothelial cells, epithelial cells and fibroblasts to recruit macrophages, neutrophils and $\mathrm{T}$ cells to the site of infection [40]. Importantly IFN- $\gamma$ plays a critical role in conveying antiviral signals from the innate to the adaptive immune response in order to fully activate host antiviral immunity. Upon receiving the IFN- $\gamma$ signal, APCs increase expression of MHC class II and costimulatory molecules which in turn facilitates CD4+ $\mathrm{T}$ cell activation and initiation of the adaptive immune response against viral infection. IFN- $\gamma$ also induces the expression of IL- 12 by APCs. IL-12 not only activates NK cells, a major antiviral cellular component of innate immunity, but also drives CD4+ Th1 T cell development, a process that is crucial in controlling viral infection.

\subsection{IFN- $\gamma$ as a therapeutic agent for virus infection}

Though a hallmark for Th1 response that results in strong antiviral activity, IFN- $\gamma$ as an antiviral therapy for HIV has generated disappointing results when tested clinically. Even with its ability in enhancing CTL and NK cell activity, IFN- $\gamma$ failed to decrease HIV viral loads in patients in a clinical trial designed to evaluate the toxicity and efficacy of IFN- $\gamma$ [40]. Thus, the focus of IFN- $\gamma$ and HIV has shifted from using it as a monotherapy to combining it with highly active anti-retroviral therapy (HAART). HAART is a combination of two or more anti-retroviral drugs that inhibits HIV replication and has dramatically reduced the HIVassociated morbidity and mortality. However, the occurrence of opportunistic infections remains a serious problem in HARRT treated HIV patients due to impaired T cell immunity. IFN- $\gamma$ has been used with positive result as treatment for HIV-associated opportunistic infections with or without HARRT to reconstitute the immune response in HIV patients [41]. With the importance of IFN$\gamma$ in the host Th1 response, several groups incorporated IFN- $\gamma$ into DNA vaccine regimes as an adjuvant in HIV animal models [40].
However, the results were not impressive as IFN- $\gamma$ did not improve or only marginally improved the protective immune responses against subsequent viral challenges. In addition to the possible use in HIV treatment, IFN- $\gamma$ was also considered as a treatment option for HCV and HBV. However, in a recent report, addition of IFN- $\gamma$ in an HCV treatment regimen did not successfully suppress HCV infection in patients who were non-responders to PEG-IFN/ ribavirin [42]. However, in this study, the timing of the IFN- $\gamma$ treatment may be an issue, as it was added later in the treatment regimen and it has been reported that virus elimination in the early phase of treatment is closely associated with a better SVR rate. Although the results of using IFN- $\gamma$ in HCV and HBV treatments have been controversial, IFN- $\gamma$ may have additional benefits. A study done by $\mathrm{Wu}$ et al. showed that HBsAg positive patients with stage 2-4 hepatic fibrosis achieved a significantly improved fibrotic score after 9-months of IFN-ytreatment [43].

\section{Type III interferon: interferon-lambda (IFN- $\lambda$ )}

\subsection{IFN- $\lambda$ signaling pathway}

Human Type III IFNs or IFN- $\lambda$ s, including IFN- $\lambda 1$, IFN- $\lambda 2$ and IFN- $\lambda 3$ (or IL-29, IL-28A and IL-28B respectively), were identified by two independent groups in 2003 . Though structurally related to IL-10-related cytokines, IFN- $\lambda$ can induce antiviral activity in a variety of target cells that express the IFN- $\lambda$ receptor [44]. Thus, they have been functionally classified as a new type of IFN. The IFN$\lambda$ proteins bind and signal through a receptor complex composed of the IL-10R2 chain (also an essential part of the receptor complexes for IL-10, IL-22, and IL-26), and the IFN- $\lambda$ R1 chain (also known as IL-28RA) which is utilized only by IFN- $\lambda$. Although IFN- $\lambda$ can be expressed by virtually all cell types that can be infected with virus, the IFN- $\lambda$ R1 subunit is constitutively expressed by limited cell types, primarily cells of epithelial origin. IFN- $\lambda$ R1 was shown to also be expressed on some blood immune cells including B cells, $\mathrm{T}$ cells, DCs and macrophages. However, these cells expressed a short IFN- $\lambda$ receptor splice variant (sIFN-IR1/sIL-28R1) which results in a weaker signaling strength when stimulated with IFN- $\lambda$ [45]. In contrast, fibroblasts, endothelial cells and most leukocytes do not express the full length IFN- $\lambda$ R1 chain; therefore, they do not response to IFN- $\lambda$ stimulation. IFN- $\lambda$ first binds to the IFN- $\lambda$ R1 chain, resulting in a conformation change that facilitates the recruitment of IL-10R2. Formation of the IFN- $\lambda$ and IFN- $\lambda$ receptor complex leads to JAK activation, followed by tyrosine phosphorylation of the intracellular domain of the IFN- $\lambda$ R1 chain, resulting in STAT1 and STAT2 activation (Fig. 1). Signaling through either IFN- $\lambda$ or IFN- $\alpha$ receptor complexes results in the activation of the same JAK-STAT signal transduction cascade; though the signaling strength induced by IFN- $\lambda$ is comparatively weaker [46].

\subsection{Antiviral activities}

Similar to Type I IFN, IFN- $\lambda$ has the ability to induce antiviral activity in target cells. It has been established that IFN- $\lambda$ can inhibit HBV replication in different murine hepatocyte cell lines, as well as the replication of a subgenomic and full length HCV replicon in a human hepatoma cell line $[47,48]$. Recent reports also demonstrated that IFN- $\lambda$ inhibits HIV- 1 replication in macrophages and primary T cells $[49,50]$. Virus inhibition by IFN- $\lambda$ was also shown in vivo when locally delivered recombinant IFN- $\lambda$ inhibited HHV-1, HHV-2 and IAV replication in the vagina and lungs [51]. Similar to Type I and II IFNs, IFN- $\lambda$ also can induce the expression of the antiviral hallmark proteins, OAS and Mx protein [52]. In addition to inhibiting virus replication, IFN- $\lambda$ can limit prolonged virus infection by up-regulating the expression levels of MHC class I proteins on the cell surface, which in turns facilitates the 
recognition and destruction of virus-infected cells by the innate immune system, and by inducing apoptosis of the virus infected cells [53].

\subsection{PEG-IFN- $\lambda$ as a therapeutic agent for HCV infection}

Due to the rapid genetic changes that render HCV resistant to drugs targeting virus replication and assembly, IFN- $\alpha$ treatment remains an effective therapy for $\mathrm{HCV}$ infection, despite the array of systemic side effects. However, as the restricted tissue expression of the IFN- $\lambda$ R1 chain ensures a localized reaction, the antiviral activity of IFN- $\lambda$ makes it a much safer and less toxic choice as a therapeutic agent for virus infection. As the preclinical studies showed that PEG-IFN- $\lambda$ inhibited HCV replication in human hepatocytes without hematological cytotoxicity, a phase IA dose escalation study in healthy volunteers was conducted in 2007 $[54,55]$. Subjects received a single dose of PEG-IFN- $\lambda$ injected subcutaneously. All testing dosages $(0.5,1.5,5$ and $7.5 \mu \mathrm{g} / \mathrm{kg})$ were well tolerated, and no IFN induced side effects were observed in the subjects. However, a few volunteers in $7.5 \mu \mathrm{g} / \mathrm{kg}$ group developed significant elevated transaminase which was considered a doselimiting toxicity and could be reversed by lowering the IFN dosage. A subsequent phase IB study was conducted to evaluate the efficacy and cytotoxicity of IFN- $\lambda$ in $\mathrm{HCV}$ infected patients, including both treatment-naïve patients and patients who relapsed after previous IFN- $\alpha$ treatment. Recruited patients received PEG-IFN- $\lambda$ with or without ribavirin weekly or bi-weekly at the dose range from 0.5 to $3 \mu \mathrm{g} / \mathrm{kg}$ for 4 weeks.

During the trial, six of the patients had elevated transaminase which resolved after stopping treatment. Overall, there was a significant decrease in the incidence of IFN- $\alpha$ type side effects, and unlike PEG-IFN- $\alpha$, PEG-IFN- $\lambda$ treatment did not exhibit significant hematological toxicity. Most importantly, patients receiving $\geq 1.5 \mu \mathrm{g} / \mathrm{kg} /$ week exhibited at least two logs reduction in viral load; four logs when combined with ribavirin treatment. Unexpectedly, two of the patients who previously were treated with IFN- $\alpha$ developed antibodies cross-reactive to IFN- $\lambda$, an observation that implies the efficacy of IFN- $\lambda$ treatment may be limited in some patients previously treated with IFN- $\alpha$. Three independent genome-wide association studies (GWASs) have identified SNPs in the IL28B gene as being associated with the outcome to treatment with PEG- IFN- $\alpha$ /ribavirin in HCV patients [56]. A 12-week phase IIA clinical study was conducted that compared the safety and antiviral activity of four fixed doses of PEG-IFN- $\lambda$ to PEG-IFN- $\alpha$ in treatment-naïve HCV patients. The percentage of patients with undetectable virus was significantly higher in those with the favorable genotype (86\%) compared to those carrying the risk allele (50\%). These results suggest that the efficacy of treatment with PEG-IFN- $\lambda$ will differ according to IL28B genotype [54]. The most recent phase IIB trial was designed to assess the safety, efficacy, and pharmacokinetics of fixed dose PEG-IFN- $\lambda$ vs. PEG-IFN- $\alpha$ in 526 treatment-naïve patients infected with HCV genotypes $1,2,3$ and 4 . Patients received PEG-IFN- $\lambda$ $240 \mu \mathrm{g}$, PEG-IFN- $\lambda 180 \mu \mathrm{g}$, PEG-IFN- $\lambda 120 \mu \mathrm{g}$ or PEG-IFN- $\alpha$ $180 \mu \mathrm{g}$ weekly, all in combination with daily ribavirin. The treatment period is 48 weeks for HCV genotype 1 and 4 patients who exhibited a poor response to PEG-IFN- $\alpha$ and ribavirin treatment and 24 weeks for HCV genotype 2 and 3 patients. Treatment with PEG-IFN- $\lambda$ and ribavirin achieved higher rates of rapid virologic response (RVR) and a complete early virologic response (cEVR) regardless of the HCV genotypes as compared to the treatment with PEG-IFN- $\alpha /$ ribavirin. Furthermore, there were fewer incidences of IFN- $\alpha$ type side effects, as well as fewer dose reductions for anemia in the PEG-IFN- $\lambda$ treatment group up to 12 weeks. However, the incidence of serious adverse events was similar across treatment groups up to week 12 [57]. The results of the phase III trial thus far demonstrate the potential for using IFN- $\lambda$ as therapy in HCV infection. Careful titration of dosage should result in a treatment regimen that would inhibit viral replication but at the same time reduce adverse effects. Based on the success in the use of IFN- $\lambda$ for HCV therapy clinical trials, one can foresee the possible incorporation of IFN- $\lambda$ in the treatment of other viral infections.

\section{IFNs as therapeutic agents in other diseases}

In addition to antiviral therapy, IFNs also have been used as therapeutic agents in cancer and autoimmune diseases. Due to its antiproliferative, antiangiogenesis and immunomodulatory effects, IFN- $\alpha$ has been included in several cancer treatment regimens as an adjuvant. In melanoma, high-dose IFN- $\alpha 2 b$ regimen (HDI, both recombinant and pegylated forms) has been approved for use as part of the treatment as multiple metaanalyses have shown that HDI significantly increases disease-free survival and overall survival in high-risk cutaneous melanoma $[58,59]$. IFN- $\alpha$ also has been evaluated in multiple clinical trials as part of therapy regimen for renal cell carcinoma [60-63]. In these trails, patients achieved longer progression free survival when treated with low dose IFN- $\alpha$ in combination with a variety of chemotherapeutic drugs. Before the discovery of tyrosine kinase inhibitor, Imatinib, IFN- $\alpha$ was the choice of treatment for chronic myeloid leukemia (CML). While Imatinib still remains the frontline treatment for CML, several groups set out to improve the efficacy of Imatinib by combining PEG-IFN- $\alpha 2 \mathrm{a}$ or PEG-IFN- $\alpha 2 \mathrm{~b}$ into the treatment regimen. The results of these studies showed that the addition of PEG-IFN significantly reduced the number of leukemia cells in treated patients [64-66]. In 1993, IFN- $\beta$ was first approved for multiple sclerosis (MS) treatment in the USA. Currently, there are several FDA approved IFN- $\beta$ products available (Table 1 ). While flu-like symptoms are commonly observed in treated patients, IFN$\beta$ treatment for MS is considered safe and effective. Although the exact mechanism of how IFN- $\beta$ inhibits the progression of MS is unknown, its anti-inflammatory effects and its abilities to induces the generation of regulatory $\mathrm{T}$ cells, prevent leukocytes from crossing the blood brain barrier and promote apoptosis in autoreactive $\mathrm{T}$ cells make IFN- $\beta$ an attractive treatment option for MS $[67,68]$. Compared to Type I IFNs, IFN- $\gamma$ does not get utilized as broadly in the clinic. However, IFN- $\gamma$ has been shown to be effective in controlling sever idiopathic atopic dermatitis by decreasing blood eosinophil count, and inhibiting IgE synthesis and T-cell proliferation [69]. IFN- $\gamma$ also has been used in patients with chronic granulomatous disease, a disorder with a defect in the enzyme complex responsible for phagocyte superoxide generation. However, the use of IFN- $\gamma$ in these patients is to prevent the reoccurrence of infections, not as a treatment for the underlying genetic disease [70].

\section{Conclusion}

Some viruses, such as HCV, HBV and HIV, are able to evade host immune responses and cause a state of chronic infection in the host. In these infections, reducing and eliminating viral replication requires therapeutic intervention. Due to the high incidence of genomic mutation, viruses are able to adapt and develop resistance to drugs that target essential viral proteins. Thus, a treatment that could restore and strengthen the host antiviral immune response becomes crucial in controlling virus infection. The strong antiviral activity of IFN proteins and their ability to modulate the immune response make the IFNs the perfect candidates to use in antiviral therapy. However, the immune system is an extremely complicated machine that requires delicate and subtle manipulation to maintain the balance between health and disease. IFNs are such 
powerful cytokines that using them as treatments for diseases may well offset immune homeostasis by hyperactivation of the host response. In addition, as a wide range of cell types are responsive to stimulation by IFNs, the consequences of IFN use stretch beyond the immune system. Therefore, the clinical use of IFNs to successfully suppresses virus replication and contain a spreading infection will require constant monitoring of patients for potentially detrimental side effects that go beyond enhancing the host anti-viral response.

\section{Disclaimer}

The publisher or recipient acknowledges right of the U.S. Government to retain a nonexclusive, royalty-free license in and to any copyright covering the article.

The contents of this publication do not necessarily reflect the views or policies of the Department of Health and Human Services, nor does mention of trade names, commercial products, or organizations imply endorsement by the U.S. Government.

Conflict-of interest disclosure: The authors declare no competing financial interests.

\section{References}

[1] Theofilopoulos AN, Baccala R, Beutler B, Kono DH. Type I interferons (alpha/ beta) in immunity and autoimmunity. Annu Rev Immunol 2005:23:307-36.

[2] Gonzalez-Navajas JM, Lee J, David M, Raz E. Immunomodulatory functions of type I interferons. Nat Rev Immunol 2012;12:125-35.

[3] Ivashkiv LB, Donlin LT. Regulation of type I interferon responses. Nat Rev Immunol 2014:14:36-49.

[4] van Boxel-Dezaire AH, Rani MR, Stark GR. Complex modulation of cell typespecific signaling in response to type I interferons. Immunity 2006;25:361-72.

[5] Boasso A, Type I. Interferon at the interface of antiviral immunity and immune regulation: the curious case of HIV-1. Scientifica 2013;2013:580968.

[6] Stetson DB, Medzhitov R. Type I interferons in host defense. Immunity 2006;25:373-81.

[7] Rong L, Dahari H, Ribeiro RM, Perelson AS. Rapid emergence of protease inhibitor resistance in hepatitis C virus. Sci Transl Med 2010;2:30ra2.

[8] Zeuzem S, Welsch C, Herrmann E. Pharmacokinetics of peginterferons. Semin Liver Dis 2003;23(Suppl 1):23-8.

[9] Aghemo A, Rumi MG, Colombo M. Pegylated interferons alpha2a and alpha2b in the treatment of chronic hepatitis C. Nat Rev Gastroenterol Hepatol 2010; 7:485-94

[10] Gibbert K, Schlaak JF, Yang D, Dittmer U. IFN-alpha subtypes: distinct biological activities in anti-viral therapy. Br J Pharmacol 2013;168:1048-58.

[11] Vezali E, Aghemo A, Colombo M. Interferon in the treatment of chronic hepatitis C: a drug caught between past and future. Expert Opin Biol Ther 2011;11:301-13.

[12] Sulkowski MS, Cooper C, Hunyady B, Jia J, Ogurtsov P, Peck-Radosavljevic M, et al. Management of adverse effects of Peg-IFN and ribavirin therapy for hepatitis C. Nat Rev Gastroenterol Hepatol 2011;8:212-23.

[13] Zhao HL, Yao XQ, Xue C, Wang Y, Xiong XH, Liu ZM. Increasing the homogeneity, stability and activity of human serum albumin and interferon-alpha2b fusion protein by linker engineering. Protein Expr Purif 2008;61:73-7.

[14] Balan V, Nelson DR, Sulkowski MS, Everson GT, Lambiase LR, Wiesner RH, et al. A Phase I/II study evaluating escalating doses of recombinant human albumininterferon-alpha fusion protein in chronic hepatitis $C$ patients who have failed previous interferon-alpha-based therapy. Antivir Ther 2006;11:35-45.

[15] Zeuzem S, Sulkowski MS, Lawitz EJ, Rustgi VK, Rodriguez-Torres M, Bacon BR, et al. Albinterferon Alfa-2b was not inferior to pegylated interferon-alpha in a randomized trial of patients with chronic hepatitis C virus genotype 1 . Gastroenterology 2010;139:1257-66.

[16] Bacon BR, Shiffman ML, Mendes F, Ghalib R, Hassanein T, Morelli G, et al. Retreating chronic hepatitis $\mathrm{C}$ with daily interferon alfacon-1/ribavirin afte nonresponse to pegylated interferon/ribavirin: direct results. Hepatology 2009;49:1838-46.

[17] Sjogren MH, Sjogren Jr R, Lyons MF, Ryan M, Santoro J, Smith C, et al. Antiviral response of HCV genotype 1 to consensus interferon and ribavirin versus pegylated interferon and ribavirin. Dig Dis Sci 2007;52:1540-7.

[18] Au JS, Pockros PJ. Novel therapeutic approaches for hepatitis C. Clin Pharmacol Ther 2014;95:78-88.

[19] Kiser JJ, Flexner C. Direct-acting antiviral agents for hepatitis C virus infection. Annu Rev Pharmacol Toxicol 2013;53:427-49.

[20] Lavanchy D. Hepatitis B virus epidemiology, disease burden, treatment, and current and emerging prevention and control measures. J Viral Hepat 2004; 11:97-107.

[21] Kwon H, Lok AS. Hepatitis B therapy. Nat Rev Gastroenterol Hepatol $2011 ; 8: 275-84$
[22] Wang L, Zou Z, Liu C, Liu X. Immunotherapeutic interventions in chronic Hepatitis B virus infection: a review. J Immunol Methods 2014.

[23] Organization WH. Hepatitis B.

[24] Huang R, Hao Y, Zhang J, Wu C. Interferon-alpha plus adefovir combination therapy versus interferon-alpha monotherapy for chronic hepatitis B treatment: a meta-analysis. Hepatol Res: Off J Jpn Soc Hepatol 2013:;43:1040-51.

[25] Wang YD, Zhao CY, Wang W, Shen C, Lu HZ, Zhang L, et al. Improved efficacy by individualized combination therapy with Peg IFN-a 2a and ADV in HBeAg positive chronic hepatitis B patients. Hepato-gastroenterology 2012;59: 680-6.

[26] Huang Z, Deng H, Zhao Q, Zheng Y, Peng L, Lin C, et al. Peginterferon-alpha2a combined with response-guided short-term lamivudine improves response rate in hepatitis B e antigen-positive hepatitis B patients: a pilot study. Eur J Gastroenterol Hepatol 2013;25:1165-9.

[27] Moucari R, Boyer N, Ripault MP, Castelnau C, Mackiewicz V, Dauvergne A, et al. Sequential therapy with adefovir dipivoxil and pegylated interferon alfa-2a for HBeAg-negative patients. J Viral Hepat 2011;18:580-6.

[28] Piccolo P, Lenci I, di Paolo D, Demelia L, Sorbello O, Nosotti L, et al. A randomized controlled trial of sequential pegylated interferon-alpha and telbivudine or vice versa for 48 weeks in hepatitis B e antigen-negative chronic hepatitis B. Antivir Ther 2013;18:57-64.

[29] Ahn SH, Lee HW, Kim YS, Kim JK, Han KH, Chon CY, et al. Recombinant interferon-Beta-1alpha plus ribavirin for the treatment of chronic HCV infection: a prospective, randomized, comparative pilot study. Gut Liver 2009;3: $20-5$.

[30] Inoue K, Watanabe T, Yamada M, Yoshikumi H, Ogawa O, Yoshiba M. Efficacy of interferon Beta combined with cyclosporine induction and intensified therapy for retreatment of chronic hepatitis C. Transplant Proc 2009;41:246-9.

[31] Ishikawa T, Kubota T, Abe H, Nagashima A, Hirose K, Togashi T, et al. Efficacy of the regimen using twice-daily beta-interferon followed by the standard of care for chronic hepatitis C genotype 1b with high viral load. Hepatol Res: Off J Jpn Soc Hepatol 2012;42:864-9.

[32] Itokawa N, Atsukawa M, Tsubota A, Kondo C, Hashimoto S, Fukuda T, et al. Lead-in treatment with interferon-beta/ribavirin may modify the early hepatitis $C$ virus dynamics in pegylated interferon alpha-2b/ribavirin combination for chronic hepatitis C patients with the IL28B minor genotype. J Gastroenterol Hepatol 2013;28:443-9.

[33] Goldwater PN. Randomized comparative trial of interferon-alpha versus placebo in hepatitis B vaccine non-responders and hyporesponders. Vaccine 1994:12:410-4

[34] Rizza P, Capone I, Urbani F, Montefiore E, Rapicetta M, Chionne P, et al. Evaluation of the effects of human leukocyte IFN-alpha on the immune response to the HBV vaccine in healthy unvaccinated individuals. Vaccine 2008:26:1038-49.

[35] Savan R, Ravichandran S, Collins JR, Sakai M, Young HA. Structural conservation of interferon gamma among vertebrates. Cytokine Growth Factor Rev 2009;20:115-24.

[36] Schroder K, Hertzog PJ, Ravasi T, Hume DA. Interferon-gamma: an overview of signals, mechanisms and functions. J Leukoc Biol 2004;75:163-89.

[37] Saha B, Jyothi Prasanna S, Chandrasekar B, Nandi D. Gene modulation and immunoregulatory roles of interferon gamma. Cytokine 2010;50:1-14.

[38] Gough DJ, Levy DE, Johnstone RW, Clarke CJ. IFNgamma signaling-does it mean JAK-STAT? Cytokine Growth Factor Rev 2008;19:383-94.

[39] Johnson HM, Noon-Song EN, Dabelic R, Ahmed CM. IFN signaling: how a noncanonical model led to the development of IFN mimetics? Front Immunol 2013;4:202.

[40] Roff SR, Noon-Song EN, Yamamoto JK. The Significance of Interferon-gamma in HIV-1 pathogenesis, therapy, and prophylaxis. Front Immunol 2014:4:498.

[41] Jarvis JN, Meintjes G, Rebe K, Williams GN, Bicanic T, Williams A, et al. Adjunctive interferon-gamma immunotherapy for the treatment of HIV-associated cryptococcal meningitis: a randomized controlled trial. AIDS 2012:26:1105-13.

[42] Couzigou P, Perusat S, Bourliere M, Trimoulet P, Poynard T, Leroy V, et al. Interferon-gamma with peginterferon alpha-2a and ribavirin in nonresponder patients with chronic hepatitis C (ANRS HC16 GAMMATRI). J Gastroenterol Hepatol 2013;28:329-34.

[43] Wu YJ, Cai WM, Li Q, Liu Y, Shen H, Mertens PR, et al. Long-term antifibrotic action of interferon-gamma treatment in patients with chronic hepatitis B virus infection. Hepatobiliary Pancreat Dis Int: HBPD INT 2011:10:151-7.

[44] Gad HH, Dellgren C, Hamming OJ, Vends S, Paludan SR, Hartmann R. Interferon-lambda is functionally an interferon but structurally related to the interleukin-10 family. J Biol Chem 2009:284:20869-75.

[45] Witte K, Gruetz G, Volk HD, Looman AC, Asadullah K, Sterry W, et al. Despite IFN-lambda receptor expression, blood immune cells, but not keratinocytes or melanocytes, have an impaired response to type III interferons: implications for therapeutic applications of these cytokines. Genes Immun 2009;10: 702-14.

[46] Dumoutier L, Tounsi A, Michiels T, Sommereyns C, Kotenko SV, Renauld JC. Role of the interleukin (IL)-28 receptor tyrosine residues for antiviral and antiproliferative activity of IL-29/interferon-lambda 1: similarities with type I interferon signaling. J Biol Chem 2004;279:32269-74.

[47] Doyle SE, Schreckhise H, Khuu-Duong K, Henderson K, Rosler R, Storey H, et al. Interleukin-29 uses a type 1 interferon-like program to promote antiviral responses in human hepatocytes. Hepatology 2006;44:896-906.

[48] Robek MD, Boyd BS, Chisari FV. Lambda interferon inhibits hepatitis B and C virus replication. J Virol 2005;79:3851-4. 
[49] Liu MQ, Zhou DJ, Wang X, Zhou W, Ye L, Li JL, et al. IFN-lambda3 inhibits HIV infection of macrophages through the JAK-STAT pathway. PLoS One 2012; 7:e35902.

[50] Tian RR, Guo HX, Wei JF, Yang CK, He SH, Wang JH. IFN-lambda inhibits HIV-1 integration and post-transcriptional events in vitro, but there is only limited in vivo repression of viral production. Antivir Res 2012;95: 57-65.

[51] Sommereyns C, Paul S, Staeheli P, Michiels T. IFN-lambda (IFN-lambda) is expressed in a tissue-dependent fashion and primarily acts on epithelial cells in vivo. PLoS Pathog 2008;4:e1000017.

[52] Brand S, Zitzmann K, Dambacher J, Beigel F, Olszak T, Vlotides G, et al. SOCS-1 inhibits expression of the antiviral proteins 2',5'-OAS and MxA induced by the novel interferon-lambdas IL-28A and IL-29. Biochem Biophys Res Commun 2005;331:543-8.

[53] Kotenko SV, Gallagher G, Baurin VV, Lewis-Antes A, Shen M, Shah NK, et al. IFN-lambdas mediate antiviral protection through a distinct class II cytokine receptor complex. Nat Immunol 2003;4:69-77.

[54] Muir AJ, Shiffman ML, Zaman A, Yoffe B, de la Torre A, Flamm S, et al. Phase 1b study of pegylated interferon lambda 1 with or without ribavirin in patients with chronic genotype 1 hepatitis C virus infection. Hepatology 2010;52: 822-32.

[55] Ramos EL. Preclinical and clinical development of pegylated interferon-lambda 1 in chronic hepatitis C. J Interferon Cytokine Res: Off J Int Soc Interferon Cytokine Res 2010;30:591-5.

[56] Donnelly RP, Dickensheets H, O’Brien TR. Interferon-lambda and therapy for chronic hepatitis C virus infection. Trends Immunol 2011;32:443-50.

[57] Elicker J. Investigational compound PEG-interferon lambda achieved higher response rates with fewer flu-like and musculoskeletal symptoms and cytopenias than PEG-interferon alfa in Phase IIb study of 526 treatment-naive Hepatitis C patients; 2011.

[58] Ismail A, Yusuf N, Type I. Interferons: key players in normal skin and select cutaneous malignancies. Dermatol Res Pract 2014;2014:847545.

[59] Tarhini AA, Gogas H, Kirkwood JM. IFN-alpha in the treatment of melanoma. J Immunol 2012;189:3789-93.

[60] Bracarda S, Porta C, Boni C, Santoro A, Mucciarini C, Pazzola A, et al. Could interferon still play a role in metastatic renal cell carcinoma? A randomized study of two schedules of sorafenib plus interferon-alpha 2a (RAPSODY). Eur Urol 2013;63:254-61.

[61] Maroto JP, del Muro XG, Mellado B, Perez-Gracia JL, Andres R, Cruz J, et al. Phase II trial of sequential subcutaneous interleukin-2 plus interferon alpha followed by sorafenib in renal cell carcinoma (RCC). Clin Transl Oncol: Off Publ Fed Span Oncol Soc Natl Cancer Inst Mex 2013;15:698-704.

[62] Melichar B, Bracarda S, Matveev V, Alekseev B, Ivanov S, Zyryanov A, et al. A multinational phase II trial of bevacizumab with low-dose interferon-alpha2a as first-line treatment of metastatic renal cell carcinoma: BEVLiN. Ann Oncol: Off J Eur Soc Med Oncol/ESMO 2013;24:2396-402.

[63] Rini BI, Bellmunt J, Clancy J, Wang K, Niethammer AG, Hariharan S, et al. Randomized phase III trial of temsirolimus and bevacizumab versus interferon alfa and bevacizumab in metastatic renal cell carcinoma: INTORACT trial. J Clin Oncol: Off J Am Soc Clin Oncol 2014;32:752-9.

[64] Johnson-Ansah H, Guilhot J, Rousselot P, Rea D, Legros L, Rigal-Huguet F, et al. Tolerability and efficacy of pegylated interferon-alpha-2a in combination with imatinib for patients with chronic-phase chronic myeloid leukemia. Cancer 2013;119:4284-9.
[65] Simonsson B, Gedde-Dahl T, Markevarn B, Remes K, Stentoft J, Almqvist A, et al. Combination of pegylated IFN-alpha2b with imatinib increases molecular response rates in patients with low or intermediate-risk chronic myeloid leukemia. Blood 2011;118:3228-35.

[66] Talpaz M, Hehlmann R, Quintas-Cardama A, Mercer J, Cortes J. Re-emergence of interferon-alpha in the treatment of chronic myeloid leukemia. Leukemia 2013;27:803-12.

[67] Kay M, Hojati Z, Dehghanian F. The molecular study of IFNbeta pleiotropic roles in MS treatment. Iran J Neurol 2013;12:149-56.

[68] Rommer PS, Stuve O. Management of secondary progressive multiple sclerosis: prophylactic treatment-past, present, and future aspects. Curr Treat Option Neurol 2013;15:241-58.

[69] Misery L. Therapeutic perspectives in atopic dermatitis. Clin Rev Allergy Immunol 2011;41:267-71.

[70] Marciano BE, Wesley R, De Carlo ES, Anderson VL, Barnhart LA, Darnell D, et al. Long-term interferon-gamma therapy for patients with chronic granulomatous disease. Clin Infect Dis: Off Publ Infect Dis Soc Am 2004;39:692-9.

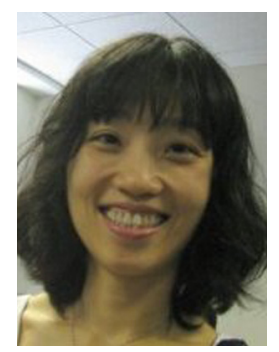

Fan-ching Lin, PhD, is a postdoctoral fellow at Nationa Cancer Institute in Frederick in Dr. Howard Young's laboratory. She earned her doctorate in Immunology at University of California, Davis where she studies adaptive immunity and vaccine research in SIV. Her areas of expertise include immune regulation and inflammation especially the effect of proinflammatory cytokines in hematopoiesis stem cells.

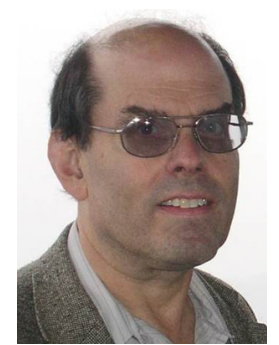

Howard Young is a Principal Investigator in the Laboratory of Experimental Immunology, Cancer and Inflammation Program. Center for Cancer Research at the National Cancer Institute at Frederick, in Frederick, MD. He has been working on varying aspects of innate immunity for over 30 years, and has experience in studying cytokine gene expression and signaling, the biology and molecular biology of NK cells, the generation and analysis of murine macrophage cell lines and immune signaling networks. His studies have involved molecular characterization of the transcriptional regulation of Interferon-g and most recently, his laboratory has developed a novel mouse model of lupus and aplastic anemia based on chronic expression of low levels of this important immunoregulatory molecule. He is a Past President of the International Society for Interferon and Cytokine Research and currently edits the society newsletter and he also served as Chair of the Immunology Division of the American Society for Microbiology. He also established an NIH Interferon Club, focused on the biology of the interferons in order to bring together interferon research from across the NIH in order to promote interactions and collaborations. 